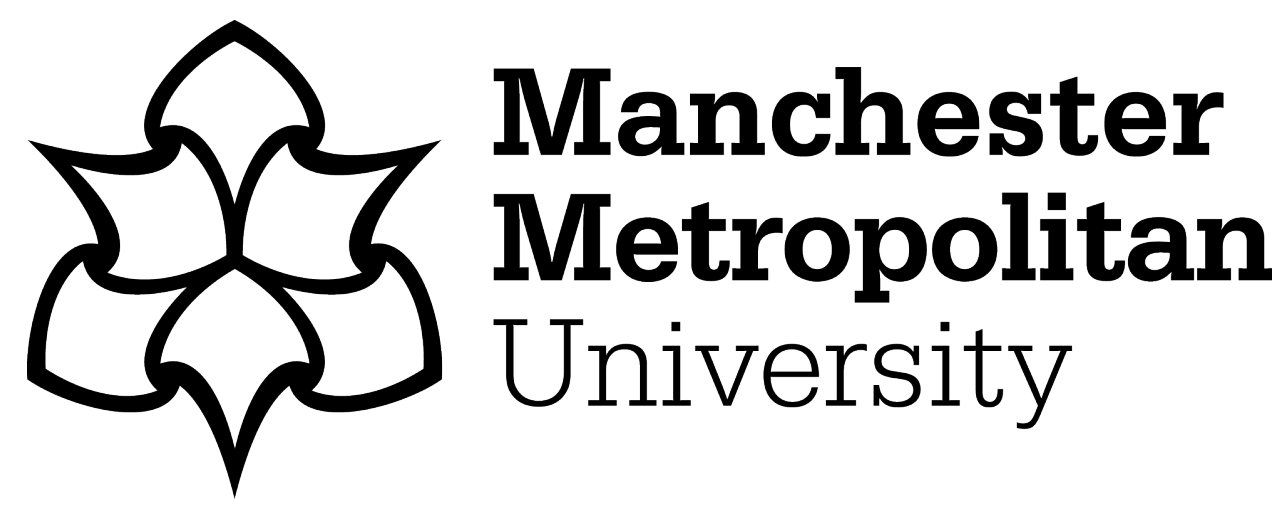

Bennett, Julia (2014) Researching the intangible: a qualitative phenomenological study of the everyday practices of belonging. Sociological Research Online, 19 (1). pp. 67-77. ISSN 1360-7804

Downloaded from: https://e-space.mmu.ac.uk/558602/

Version: Accepted Version

Publisher: SAGE Publications

DOI: https://doi.org/10.5153/sro.3187

Please cite the published version 


\title{
Researching the intangible: a qualitative phenomenological study of the everyday practices of belonging
}

\begin{abstract}
How can the intangible aspects of everyday life be uncovered? A phenomenological approach has its origins in the everyday but also allows everything to be questioned. In studying belonging a phenomenological approach supported by a variety of qualitative methods produced a wealth of 'insider' information that could have been missed using more traditional methods. The research was based around multi-generational family groups as a family narrative focuses on relations between different family members over the generations rather than on an individual biography. Biographical interviews in family groups allowed families to talk about their lives together. Diaries put the direction of the research in the hands of the participants thus reversing, to some extent, the traditional power relations between researcher and researched. Through written and photo diaries participants shared details of their daily lives which might have been more difficult to elicit in a formal interview situation. The photos allowed the researcher to 'visit' places which are a part of the daily life of participants in a subtle and non-intrusive manner. These research approaches privilege the voices of the participants in research into their lives. Through demonstrating the richness of the data collected this article argues that such approaches could be used more widely.
\end{abstract}

\section{Keywords}

Belonging; phenomenology; qualitative methods; visual methods; diaries; photo-elicitation; family; place

\section{Why is researching belonging problematic?}

Belonging can be understood as an everyday 'ordinariness' that is unconscious (May 2011: 370). Considered as part of everyday life belonging is simply there, at hand. How one comes to belong is more likely to be considered when one does not belong, which is perhaps why there is more academic literature relating to not belonging than to belonging (Ahmed 2007; Brah 2002; Bhabha 1996; Said 2000; Valentine et al 2009). In sociological research belonging is usually looked at by asking people how they feel; whether they feel comfortable, at home, in place (Savage et al 2005; Christensen 2009). Research which is concerned with a level of engagement with the world not usually thought about cannot be conducted by simply asking people about their feelings. This was the problem I faced in conducting research into how people who have lived in the same place all their lives do belonging.

How can we uncover the intangible aspects of everyday life? Everyday life is difficult to research because it is by its very nature habitual and taken-for-granted; it is what we do, rather than think, part of our habit, or embodied, memories (Connerton 1989). In questioning an act, such as in an interview, the seemingly seamless interaction between person and environment dissipates and the nature of the practice as an embodied practice is lost (Bourdieu 1977: 120). Asking for a response to a 'why' question requires using rational linguistic structures, and yet the 'why' of an act may not be seen as relevant by the participant (Schutz \& Luckmann 1974: 251), or an act is seen, by both interviewer and interviewee, to be so mundane that it is never questioned at all. It is only in the process, in the doing, that the underlying meaning structures become clear (Jackson 1993). Phenomenology gives us a way of understanding the contingency of this taken-for-granted attitude by allowing for a prereflective engagement with things in the world. 
A phenomenological approach has its origins in the everyday but also allows preconceived understandings to be questioned. In grounding explanation 'in the first-order construction of the actors' (Aspers 2004: 2) this approach also fulfils the requirements of an ethnography that understands knowledge to be constructed through practical action within the world (Bourdieu 1977: 96). Taking a phenomenological approach gives what I call a 'sideways' perspective that is needed to refrain from objectifying research participants and their lives, whilst at the same time not becoming a part of their life-world and therefore being unable to question its norms and values. This way of looking 'sideways' at the everyday practices of this group of people approaches the study of everyday actions (in my case belonging) from a different angle from the perhaps more obvious ethnographic methods often used to study belonging such as participant observation (Blokland 2001; Degnen 2005; Fortier 1999). I did not want participants to 'think through' answers and formulate rational responses to what were bound to seem naive questions about their lives (Eberle 2013: 126). Questioning the 'day to day assumptions and practices' which are 'rooted in distinct patterns of social relationships' (Morgan 2005: 647), may present difficulties for the researcher in formulating a question that would be relevant to the interviewee.

After a more detailed explanation of the phenomenological methodology and the research methods used, this article demonstrates, using examples, how taking a user-driven phenomenological approach to ethnographic research can generate qualitatively rich data on the intangible aspects of everyday life. The article concludes by discussing the problems and benefits of these methods in researching the intangible.

\section{What is Phenomenology?}

Phenomenology is, essentially, the description or explanation of directly perceived phenomena (Vaitkus 2000: 273). This can either be the material object, the subject of a picture, or a memory or feeling: it is the consciousness of something (Ferguson 2006: 24). The method of phenomenology is a particular way of seeing the world as contingent, as 'just one of a series of possibilities' (Ferguson 2006: 48 - 9). Investigation of this level of understanding is difficult: there is no 'where' from which to observe objectively as we are always already immersed in and surrounded by the phenomenal world. Phenomenology developed in opposition to philosophy's radical dualism whereby consciousness and 'reality' are located in separate spheres. Husserl (1964) is seen as the founding father of this approach which Heidegger and others then built on. Husserl argues that in adopting what he calls the 'natural attitude', people take their surroundings for granted and do not question them. Heidegger (1962) reversed the philosophical primacy of the theoretical over the practical by proposing a phenomenology of the everyday. He realised that philosophy's engagement with the occurrentness of objects, their presence at hand, is predicated on a prior, practical level of engagement with the world which is not reflective and is organised by activity rather than conscious interaction with objects. This is what he termed the ready-at-hand (zuhanden) practical engagement with things in the world. For example, when using my pen to write I am unaware of the pen in my hand until it runs out of ink. It then becomes vorhanden, that is, a separate presence. It is the act of writing that engages me, not the tool through which I accomplish the act. Everyday life, for Heidegger, is concerned with these practical and personal concerns (Frede 2006: 59).

A phenomenological understanding of the world always incorporates the past and future giving a sense of continuity over time. There is, in a phenomenological sense, no outside, 
objective view of the passage of time but we travel through time as we effect the daily tasks of living (Merleau-Ponty 1962) The three temporal strata exist simultaneously: Schutz's worlds of potential, restorable and actual reach (Schutz \& Luckmann 1974) containing future, past and present life-worlds. These are connected through an on-going 'stock of knowledge' passed between the generations, allowing for shared practices over time. Schutz (1970) used Husserl's phenomenological ideas of the life-world to pursue a particularly social phenomenology which is useful here.

Phenomenology teaches us to engage with what we actually see, rather than perceiving the world through a myriad of cultural filters (whilst also understanding that the researcher herself is always already immersed in a cultural world) and therefore is a useful tool to understand the everyday. A phenomenological approach sees the world as an array of contingent possibilities. Understanding that 'it doesn't have to be like this' allows embedded (and embodied) assumptions and ways of being/doing to be questioned. This is accomplished through what Husserl calls the phenomenological reduction, that is bracketing our everyday knowledge and commonsense understandings. What the researcher 'knows' has to be set aside in order to experience the world in-itself rather than to conceptualise it. This opens up the researcher to the possibility of a reflective attentiveness to the life-world(s) being researched (Ferguson 2006: 48-9).

In taking a phenomenological approach the researcher attempts to grasp the world in its 'presence-at-hand' (vorhanden-ness), that is, at a theoretical level of understanding, rather than what is taken-for-granted (zuhanden). The problem is that, as Husserl realised, most people accept the world as taken-for-granted most of the time (Aspers, 2004). In order to access actors' own meaning structures, which they themselves may not be consciously aware of, it is necessary to examine what they actually do either through daily accounts or observation (Miller, 2012). The next section describes the methods which were used in order to minimise some of these risks.

\section{How did I do the research?}

Zimmerman and Wieder's suggested solution to the problem of unobtrusively observing people in their daily lives is the 'diary: diary interview method' (1977: 481). With some modifications that was the key method used in this research into belonging and place. As place is essentially visual (Gieryn 2000: 483), photos were added to the diaries. This method, together with the post-diary interview (Zimmerman \& Wieder 1977: 484) and initial biographical interviews yielded the in-depth data required for a practical understanding of people's daily lives which started from their subjective viewpoint (Eberle 2013: 124). The diaries acted as a medium through which it was possible to conduct an unobtrusive ethnographic study in order to gain an informed subjectivity (Jackson 1993: 340).

Using multiple methods of qualitative data collection enabled me to access the necessary rich, in-depth data to metaphorically enter into the life-worlds of the participants (Aspers 2004: 9). The first interview was biographical, the chronology led by the interviewees; the diaries detailed the social and material life-worlds of the participants giving a broad overall picture of their daily lives; and the post-diary interviews used photo elicitation techniques from the photo diaries to find out more about the places people visit in the course of their daily lives. In these approaches I was influenced by Latham's (2003) account of using diaries to capture mundane daily intercourse. This unstructured approach could be seen as trawling for data - I cast the net wide and deep, not in terms of numbers of participants, but in trying to find out as 
much about their lives as possible, within the constraints of the research process. Photo diaries gave a wealth of 'insider' information that may have been missed in using more traditional methods. Participants shared details of their daily lives, such as what they ate and chance encounters with acquaintances. Inevitably there was a large variation in the quality and quantity of the data provided in the diaries. The most useful diaries included far more than the information on where people went, who they met and some idea of what they talked about which I had asked for. Where diarists treated the diary like a personal diary, or a report or letter to me (the researcher) more useful and interesting information was included such as food that was eaten, the weather, and so on. The photos allowed me to 'visit' places which are a part of the daily life of participants in a subtle and non-intrusive manner. I also undertook a real-life visit to a park with one respondent. This particular combination of methods provided an excellent and relatively unobtrusive way of 'observing' people's everyday activities, in order to engage with the interstitial space where actions and the phenomenal world collide.

Five family groups, three of two generations and two of three generations, took part in the research, along with some individuals, totalling twenty-two people in all ranging from sixteen to eighty-five years old, with a fairly even split of men and women. All participants were interviewed either as couples, family groups or individuals, interviews taking from one to two hours. Interviewing in small groups changes the dynamics of the interview to some extent, altering the power relations between interviewer and interviewees. I found this beneficial as it freed up my interviewees to have a conversation between themselves which brought up topics unlikely to have arisen during a single life story narrative. Using narrative style interview techniques helped me to bracket any preconceived theoretical notions of what belonging is and treat each narrative as a story in its own right. Ten participants then kept a photo diary for a week and six of these took part in a post-diary interview.

As far as possible, I was led by the interviewees in terms of the structure of the interviews and (within some pre-imposed limits) the content of the diaries, allowing the research to be user-driven. This handing over of control of the data to the participants took the researcher away from active participation in the construction of the data which, to some extent, minimalised the impact of her meaning structures on the data produced. Diaries and selfdirected photography give the respondents some control, reversing the usual power relations between researcher and researched, and therefore allows the researcher a unique insight into the respondents' life-worlds (Moore et al 2008: 52). In the post-diary interviews family and local stories emerged, peeling back the layers of history behind the buildings in the pictures. I took care not to impose my meanings on the pictures (Tinkler 2013). McDonald's for example is a specific restaurant when it is part of a photo diary, not a generic one. Whilst in an interview situation the respondent is making a conscious effort to communicate with the interviewer this will not necessarily be the case when taking photographs or writing a diary. The production of the images is part of a mutual process of knowledge production between informant and researcher (Pink 2006: 37), handing some power back to the informant who is the 'expert' in terms of the content and context of the photos. User-driven research approaches, such as these allow a bottom up approach taking the perspective of the respondents' life-worlds and allowing the researcher to observe disinterestedly (Ferguson 2006:50). The combination of visual, verbal and written data embraces different forms of perception and understanding to allow a relatively unobtrusive way of observing people's everyday activities and give a three dimensional representation of their lives. 
No research is straightforward and in looking at everyday practices through the lens of the family there were hurdles to overcome. In telling a personal story the aim is often to present a happy and successful self (Hollway \& Jefferson, 2000, p. 175) and where the research is family based this includes presenting a happy and successful family story. This was particularly evident where the subject of divorce was skirted around in each of the cases where a participant had been divorced. Even amongst the younger generation divorce was still seen as slightly shameful. None of the participants was really willing to problematise their lives, even where it was clear that they had gone through difficult times in the past. Although I deliberately avoided asking directly about belonging the tendency was to extol the virtues of having family and long term friendships nearby, which might be seen as aspects of traditional communities. This may have skewed the data towards an overly positive outlook.

Using photographs in social research presents its own set of ethical issues (Tinkler 2013: 195 - 208). Some of the older respondents saw a photograph as depicting an attractive image or a person which meant that some of the photos were of individuals. This partially missed the point of engaging with places although these people were always in specific places, such as the post office. Many of the photos taken by the participants are of places with which the family has some relationship such as their own homes, homes of friends, schools and churches, I have avoided publishing these pictures in order not to reveal the identity of participants. In discussing family history I was told of some 'family secrets' (Smart 2007: 108 - 132) which may not be common knowledge amongst the wider family. None of this data is included. In analysing the data some voices came through more strongly than others simply through the amount of data they provided. The younger people, for example, had shorter life story narratives and most of the 'parent' group did not complete diaries as they did not find the time to do so. The data are therefore slightly biased towards the older participants. Reading the diaries gave an intimate knowledge of these lives which might have been difficult to get from interviews alone. This gives me a 'vested interest' (Gabb 2010: 2) in the participants' lives and I would not want to interpret any data I was privileged to hear in a less favourable light than it was given. This was problematic on occasion when I was given differing stories from different family members regarding the same event. I had to take each version as the truth as far as that person remembered it and look at how their position within the story affected the telling.

By allowing for a pre-reflective engagement with things in the world a phenomenological approach gives the 'sideways' view needed to refrain from objectifying research respondents and their lives, whilst not becoming a part of their life-world which would leave the researcher unable to question its norms and values. In analysing the fit between how people talk about their lives and what they do (via diaries) it is possible to access the impact of everyday actions, not only their taken-for-granted or practical (unconsidered) involvement in people's lives (Aspers 2004). Becoming immersed in life-story narratives and diaries enabled a reflective analysis which bracketed out pre-conceived understandings of 'the everyday'. I now discuss some examples of the ways in which these different user-driven approaches 'produce explanations that are grounded in the subjective experiences of real people' (Aspers 2004: 5).

\section{How did this work in practice?}

In order to incorporate the temporal strata of Schutz's (1962) worlds of potential, restorable and actual reach I based my research around multi-generational family groups. The most indepth area of social knowledge for most people will be the family with its shared habits, 
customs and memories. Individual life stories gathered from people within a particular community can tell us about individual lives within that community, but as an extension to a biographical approach multiple stories from the same family, or kinship group, within a community begin to tell us more about how the reproduction of social life in that community takes place (Bertaux \& Delcroix 2000: 75). This is because, as Bertaux and Delcroix explain, a family narrative focuses on relations between different family members over the generations rather than on an individual biography. Talking to families brings the relationships between family members (including ancestors) to the centre of the picture. These are both the intersubjective relationships discussed above through Schutz's 'worlds of reach' and socio-structural relations.

\section{The Aspinalls}

Beryl 76 (all names are pseudonyms), has always lived in Wigan. She has three daughters of whom Janet, 52, is the eldest. They all live close by. Janet has two teenage children Tom, 18 and Lauren, 16.

The Aspinalls completed diaries across the three generations: Beryl, her daughter Janet and her two children, Tom and Lauren. On the Wednesday of the week Janet's family wrote their diaries it was Janet's wedding anniversary and all the diaries were affected in some way by this event. To Beryl her daughter's wedding anniversary is an important occasion which deserves the right gift, the children completely ignore the occasion, it is not mentioned by either of them despite it impacting on their lives. Nor does Janet herself mark the day as particularly significant; the topics of conversation when Beryl visited being particularly mundane - the dog, the weather. From what is written Beryl, rather than Janet, would appear to be at the centre of the occasion. In effect 'the anniversary' stands at the centre and Beryl, Janet, Lauren and later Tom 'dance' around it.

Beryl wrote:

Today is my eldest daughter's wedding anniversary and I couldn't find a nice card in the shop last week, I will have to go out this morning and try a different shop

Beryl added later:

Just got back from our daughter's house after delivering her card

Janet wrote: and wine seems that I bought the correct type of wine.

4pm Mother and father called with anniversary card and gift.

Discussed dog's habits, weather, shopping expeditions.

Lauren wrote:

I talked to my Gran and Grandad at about 4 o'clock. I was

mainly not listening very hard and missed their conversations.

Tom drove his parents to a restaurant before going out to meet friends and picking his parents up on his way home. Janet had visits from a sister and an aunt bringing cards and gifts as well as her parents, but she makes little of the occasion. Beryl is concerned to buy the right card and present, this occupies her day and is written about twice in her diary demonstrating the importance of her relationship with her eldest daughter.

This is a very small, personal event but nevertheless brings strands of past, present and future to bear on it. Together Janet's family, her parents, sister, aunt, children and husband mark this 
occasion: whilst they appear to be working independently they are in fact 'attending to one another', in the same way as individual musicians need to listen to each other in order to play together (Ingold 2000: 196). The family, situated across more than one household, is acting in harmony, apparently without the need for conscious thought or discussion. Different moments in time are circulating: Beryl still lives in the house that Janet moved out of on her wedding day; the pub where Janet and her husband first met is now the restaurant where Tom works and where he bought a takeaway pizza. This coincidence is mentioned only in passing in Janet's interview but adds another element of the past, alongside the house she grew up in where her parents still live, to the on-going present tense of Janet's life. These places are, for Janet, 'inalienable' containing all the relationships to her past with which they have been connected (Jones 2010: 190). There is a flow of family life both around this particular anniversary in 2010 and around all the anniversaries, past and future, which it stands for (Ingold 2008:1805).

Without the diaries this phenomenological view would not be available to an outsider, a researcher. It is only through including the whole family in the research that a four-fold view of this day is possible. The benefits of a family based approach are shown here in the wealth of detail available through the diaries. Unfortunately none of the other families managed to complete two or more diaries across generations. Most of the 'parent' generation were too busy with work and family life to give extra time to the research. A drawback of using userdriven approaches is that it depends for its success on the willingness of the participants to take on, in this case, the diary keeping tasks.

\section{Kate and Linda}

Linda, 61, has always lived in Wigan. She has two children and three grandchildren. Linda was interviewed with her daughter, Kate (34), and her mother, Ethel (85). Linda completed a diary.

When interviewing small groups where the group know each other well, the interviewer can become more audience than stage manager, if she chooses to. I found this a beneficial stance to take as it precipitated casual conversations where perhaps more was revealed than would have been in a traditional question and answer interview. Family interviews are likely to encourage this more elusive everyday speech because the people being interviewed are at ease with each other and share a 'stock of knowledge' (Schutz \& Luckmann 1974). This is shown in the following exchange between mother and daughter, Linda and Kate:

K. They used to come from Liverpool on the train because we're right on the train line

L. The filled in quarry? Oh yes, they still do that

K. They'd come in summer for a nice day, there's just hordes of them, even little children with armbands on, in the quarry.

Me Isn't it really dangerous?

K. Oh yes

L. Very dangerous.

K. So there's been a lot of crime from that because they come and they drink and whatever

L. They drink and then go in the quarry

$\mathrm{K}$. And then pinching cars to get back home [laughter] 
The laughter at the end of this exchange seems to indicate that at some level Kate and Linda realise they are creating a stereotype of an 'other'. This could be read as Kate and Linda positioning themselves as morally superior people who understand the dangers of drinking and swimming and who know how to look after their children properly (Skeggs 2009). The data here is the kind of conversational chat that would not emerge during a straightforward interviewer/interviewee encounter and yet it gives an insight into how these two women view particular 'others' who visit 'their' place. The meaning structure is understood by mother and daughter although I still need to interpret it, both at the time of the conversation, when I ask 'isn't it really dangerous' and, as second order construct, through analysis of the data, where the 'othering' that is taking place becomes clear (Aspers 2004).

This kind of conversation could not have taken place with just myself and one interviewee present and clearly shows the more relaxed, conversational data that can stem from small group interviews where the participants know each other well. By relinquishing control of the interview into the hands of the participants, allowing them to 'talk amongst themselves' rather than bombarding them with questions, I was able to reach a greater depth of understanding of their life-world and stock of knowledge (Schutz 1962).

Not all my participants were able to persuade other family members to take part, a particular difficulty with family-based research. Individual biographical narratives nevertheless provided a view of family life as here with Joan and how she can trace much of her life through her association with the local park.

\section{Mesnes Park: Joan's Life Story}

Joan, 66, has always lived in/near Wigan, and now lives in the house she grew up in. She has a son and a daughter and six grandchildren but was the only family member to be interviewed. She completed a diary.

In revisiting Joan after her initial biographical interview to conduct a post-diary interview I was able to ask to be shown around the park which stood out as an important part of her life. The walk around the park pulled together the reminiscences from her biography, creating the park as a material place for me and demonstrating practically the concepts of overlapping worlds of reach within one person's life.

Joan has been visiting the park for as long as she can remember, first with her parents, then her children and now her grandchildren and much of her life story can be traced out there. Joan has had a continuous relationship with the park and at times her childhood and adult selves overlap in different places, bringing her childhood self into the present. Whilst Joan still visits the park regularly her park landscape is heavily coloured by her 1950s childhood:

Every Sunday, me Mum and Dad'ld get dressed up and we had outfits that we only kept for Sunday, Sunday best, we'd go to church, we'd have a lovely Sunday dinner, roast beef, Yorkshire pudding, the whole thing, then we'd all get dressed up and go in the park and there would be hundreds of mums and dads doing the same thing. And inside the cafe there was like what they called a 'mezzanay' and you could sit up on the balcony and look down below, and we used to have milk shakes and ice 
cream and we used to chat, 'cos there was no televisions in them days and it was a place where everybody went.

These activities that 'everybody' undertook, in the same way that today 'everybody' watches television, connect Joan to a time in the past although the place itself is a part of her present. In talking about or visiting the park Joan constantly 'bumps into' her childhood self, the Victorian Wiganers she could be descended from, her young grandchildren and her potential future great-grandchildren (Leach 2002: 132). Rather than being fixed in one imagined version of the past the park circulates around and through Joan's life from childhood to grandmotherhood and back again:

and in the middle of the lake there's a great big island and as a child I always wanted to go on there, ... and then about five years ago they decided that all the middle of the island needed replanting, they put a pontoon down and we were actually allowed to walk on the pontoon, I said all my youth as a child, I wanted to come on here ... and it's really a lovely island now...

This is not a linear narrative. The telling of the story, through our walk, veers from grandchildren to Joan's own childhood, to Victorian Wigan, to more recent events; the future, in the shape of restoration plans and growing grandchildren, is evident as well as the past. Worlds of restorable, actual and potential reach for Joan, are all contained within the environs of the park. In walking through the park together I am able to gain that sideways, phenomenological look into her life-world. Our walk around the park took in her grandchildren playing on the swings, to the duck pond, past the statue and to the cafe and finally for a look at the park keeper's lodge. The rhythm of Joan's life moved forward and backward in time as we walked, as did the rhythm of the life of the park from the present of dilapidated swings to the past of the statue of the MP who brought clean water to the town and to the future of the cafe's display of restoration plans. Through the rhythm of the walk Joan appropriated the space of the park (de Certeau 1984), bringing a public space into her own particular life story. The combination of Joan's biographical interview and the walk to the park which featured heavily in her life story brought the tensions of past and future in Joan's life into focus. Walking allows for a proprioceptive, that is an embodied understanding of place, rather than a purely visual one (de Certeau 1984; Gray 1999; Jackson 1983; Vergunst 2010). Walking is a form of non-propositional knowledge where conscious thought is absent. I did not have to share Joan's 'stock of knowledge' (Schutz 1962) to share in the experience of walking through the park. In walking with Joan I was able, albeit briefly, to share in her life-world and participate materially in 'her' place (Emmel \& Clark 2009).

The written diaries afforded a different kind of data - a life spread over a week rather than the sixty plus years of Joan's association with the park. John's diary was particularly interesting in the way it brought to life relationships ranging from people he knows by sight at the gym to friendships going back forty years.

\section{John and his communities}

John, 61, a retired engineer, has always lived in Wigan. He and his eldest daughter were interviewed and he completed a diary 
The sense of community that comes from the diaries is one 'constructed through a myriad of everyday discursive practices' (Martin 1997: 109). The gym, the school, the church, the shops, his house and his neighbours are all produced through the rhythms of John's life, the activities that make up his everyday life and the people who populate his life-world. His everyday life is an ongoing process constantly recreating lines of connection.

John, as becomes clear through reading his diary, is likely to bump into people he knows every time he goes out and at the gym John also meets his particular friend Simon.

'Go to [...] gym, meet fellow gym enthusiasts also personal friend [Simon], topics discussed, How cold the weather is!'

They meet up again at Mass on Saturday, as both are part of the same church 'community'. On another visit to the gym on Sunday John meets other friends, whom he usually sees at the pub every week. On the surface, John's belonging to the gym bears many similarities to the elected belongings to clubs and associations which Stacey (1960), Savage et al (2005) and other community studies (Bell \& Newby 1971) describe. However, rather than being the central pillar of John's belonging as the Parent Teacher Associations can be for newcomers to a place (Savage et al 2005), the gym serves to point up John's embeddedness in the place served by the gym: each time he visits (three times over the course of this week) he meets friends from beyond the borders of the gym 'community'. These are not friendships or acquaintances associated only with a particular place but are part of the wider fabric of John's life. This complex tangle of relationships only becomes visible through the noting down of these chance encounters in John's diary which gave me, the researcher, a privileged glimpse into his life in a way that would not be achievable through the relatively formal situation of an interview (Emmel \& Clark 2009). The diaries gave a sideways perspective on these lives that then enabled me to see how their daily practices connect them to their place and their communities and to how they 'do' belonging.

Combining the diaries with photos gave me the insight into places that a focus on belonging in place needed.

\section{Everyday Places}

In the post-diary interviews I asked people to talk about their photos in terms of what the place means to them, and at the end of the interview I asked them to place their photos in order starting with the place they felt most attached to. This gave some surprising results throwing up places such as a railway station and a garage (see below) as well as places more typically iconic of the area such as a Victorian shopping arcade and a mill. This eclectic mix of places which have meaning for people highlights the benefits of getting the participants to take their own photos. In doing so we were able to discuss their life-worlds and access meaningful places, and the things they do there, that would otherwise be likely to be overlooked. Although participants spoke about the places they photographed as part of the 'real world' (Alexander 2013: 7.14) there were also ambiguities. The presentation of familiar places in the context of a photograph, a format more usually associated for many of these respondents outwith the context of the everyday, threw up ambiguities around their feelings about the places. The photos stood in for the 'real' place and in doing so drew out the relationships of belonging (or dislocation) that the photographers feel for these places; they spoke, indirectly, of their inalienable connections to these places (Jones 2010). 
The centre of Wigan (where I undertook my research) is dominated by the Parish Church tower which looms over the area known as 'the cross' (Figure 1).

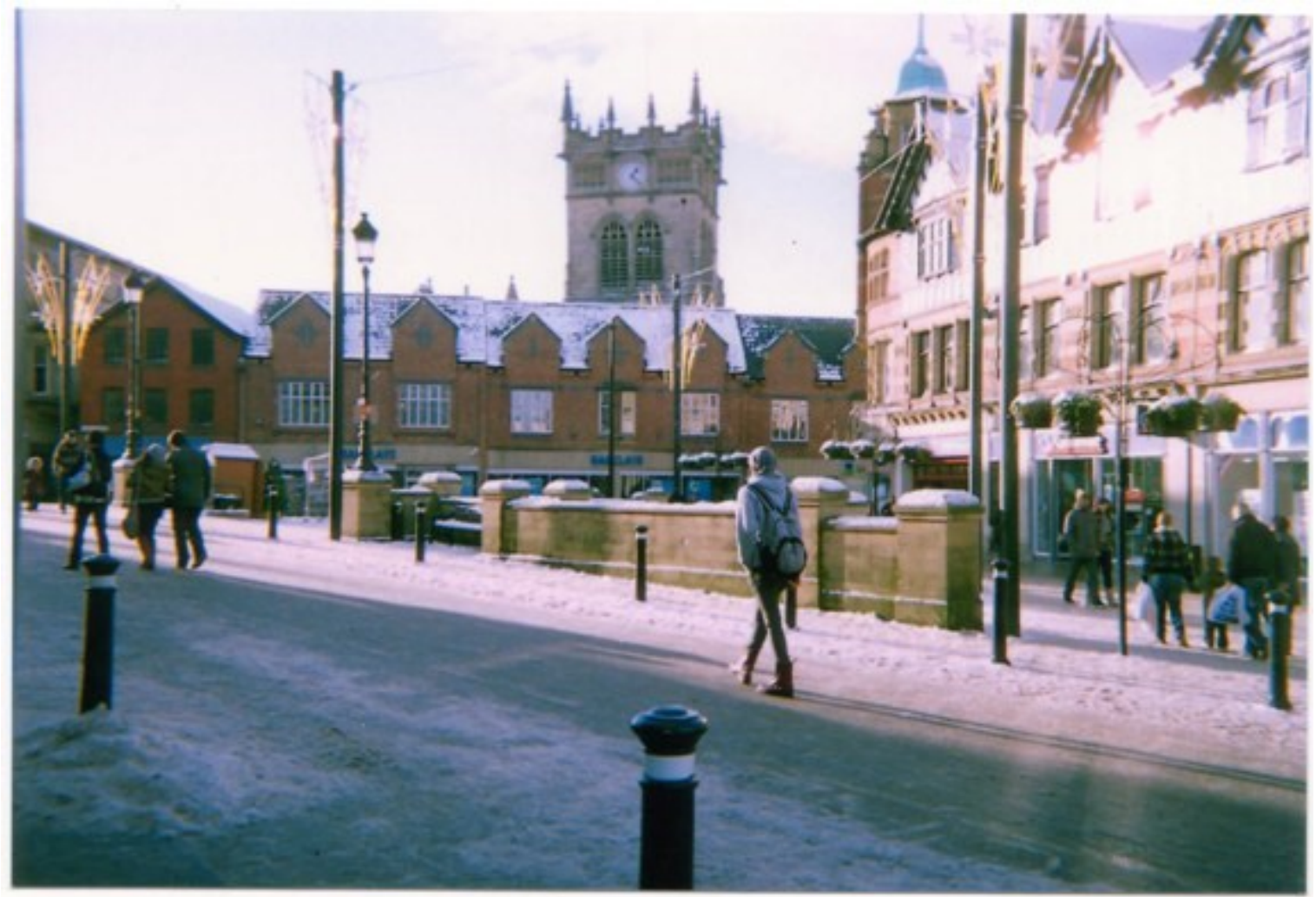

Figure 1: Wigan Parish Church

So the Parish Church, I don't know it the same as, well I don't use it at all, I think I've only been in there once but I've not got very much knowledge of [it] really, um but I've walked there hundreds and hundreds of times though because you can walk, you can park at the back there and walk through from that direction into Wigan.

(John's post-diary interview)

The Parish Church (Figure 1) is a place on the margins of John's life but a central landmark within the town he has lived in all his life. Despite John's unfamiliarity with the interior of the Parish Church through his bodily engagement, through walking past it, this place, the church and its grounds, is a vital component in John's implicit, phenomenal, knowledge of Wigan (Casey 2001; Leach 2002). The inability to articulate what is, in one sense obvious that John has a lifelong connection with these slabs of stone - is a theme of narratives of the mundane activities of daily life, overcome to some extent through the use of photographs which give the conversation a focus on place. These connections to his past are hidden within John's narrative, their 'zuhanden' nature as part of a practical level of engagement with the world that can be prised apart to reveal the occurentness of John's feet wearing down the stone paving. It is only through talking about the photo that John realised his lack of knowledge of the church at the same time emphasising his bodily connection to it. These are both aspects of the meaning structure of the church for John: his lack of cognitive knowledge in terms of the history of the church and his bodily knowledge through walking past it 
'hundreds and hundreds of times'. It is in these un-thought-about connections to places that a deep-seated belonging to place can begin to be explored.

Janet (52) is one of the Aspinalls (see above). She completed a diary.

Janet's photos also delved into connections in her life which she would not usually think about.

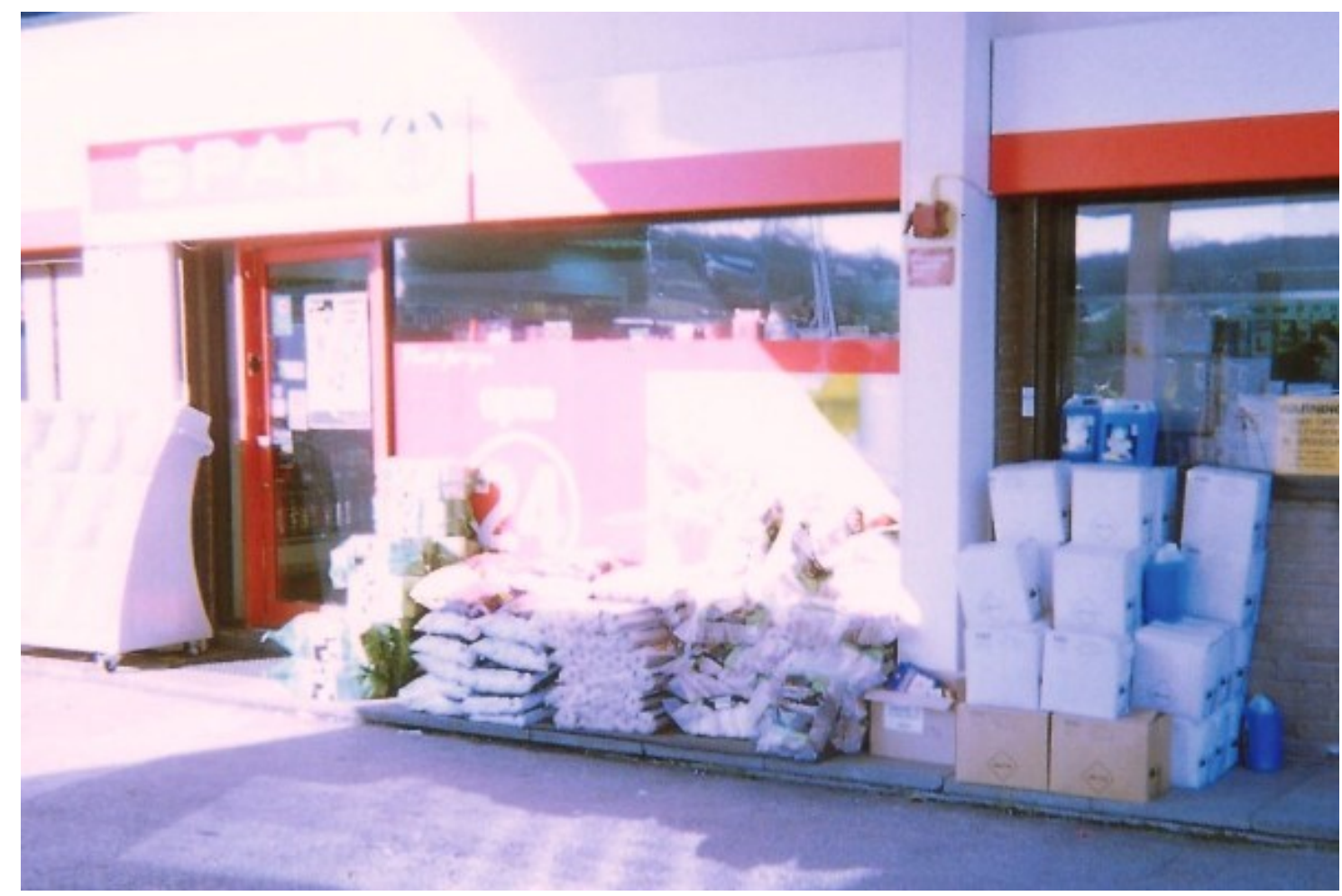

Figure 2: Spar garage

Janet chose this Spar garage (Figure 2) as one of the places included in her diary that she is most attached to. This attachment is through her friend, whom she has known for over thirty years:

... then her children and my children and you know. I've been going to that garage since I passed my driving test.

The picture encapsulates the world as it is experienced by Janet, the actor's first order construct necessary to phenomenological research (Aspers 2004). On to this I, as researcher, can build the second order constructs of the theoretical. So here worlds of past and future are invoked due to the implicit continuation of the relationship: 'I go a lot'. Janet and her friend who has worked there for many years, are 'fully immersed' in the place through their ongoing relationship with the place and each other, their shared 'worlds of actual reach'.

The photo diaries opened up a world of mundane activities that are undertaken without thought or consideration. It is unlikely that this place would have been spoken of in an interview with Janet without the photo as a prompt. Through talking to people about the actual places they visit during their week a different type of connection is unearthed than would be found through speaking of 'important' places in people's lives. The photos help to unpick the threads of Janet's life by deconstructing it into its vorhanden parts. Buying petrol 
is not something Janet considers to be an important part of her life until confronted with a photo in the out of the ordinary interview situation. Suddenly the buying of petrol can be seen for what it is: a visit to a friend, a chat. Photos of places we encounter in our everyday lives take them out of their everyday zuhanden-ness and allow us to reflect on them. The photo offers a glimpse of the taken-for-granted nature of the world for those who live in it, whilst at the same time destabilising the familiarity of the world for the participant allowing it to be seen as contingent.

Val (65) has lived in or close to Leigh all her life. She is married to Keith, 66, who moved to Wigan on his first marriage and has lived in Leigh for twenty years. Between them they have three children and six grandchildren. Val completed a diary.

This is what Val said about the photo of Bradshawgate in Leigh (Figure 3) at her post-diary interview:

Leigh. Looks funny when you take its photograph. You'd think, my God, if you'd gone for a day out you'd think let's go somewhere else but you don't see it really. This big red building used to be the Co-op and both my parents worked for the Co-op, not this one but you know the whole Co-op movement and that's how they met. Yes it isn't beautiful but it's the people, the people are very nice, they're very friendly, it's got a sense of community, we're very lucky.

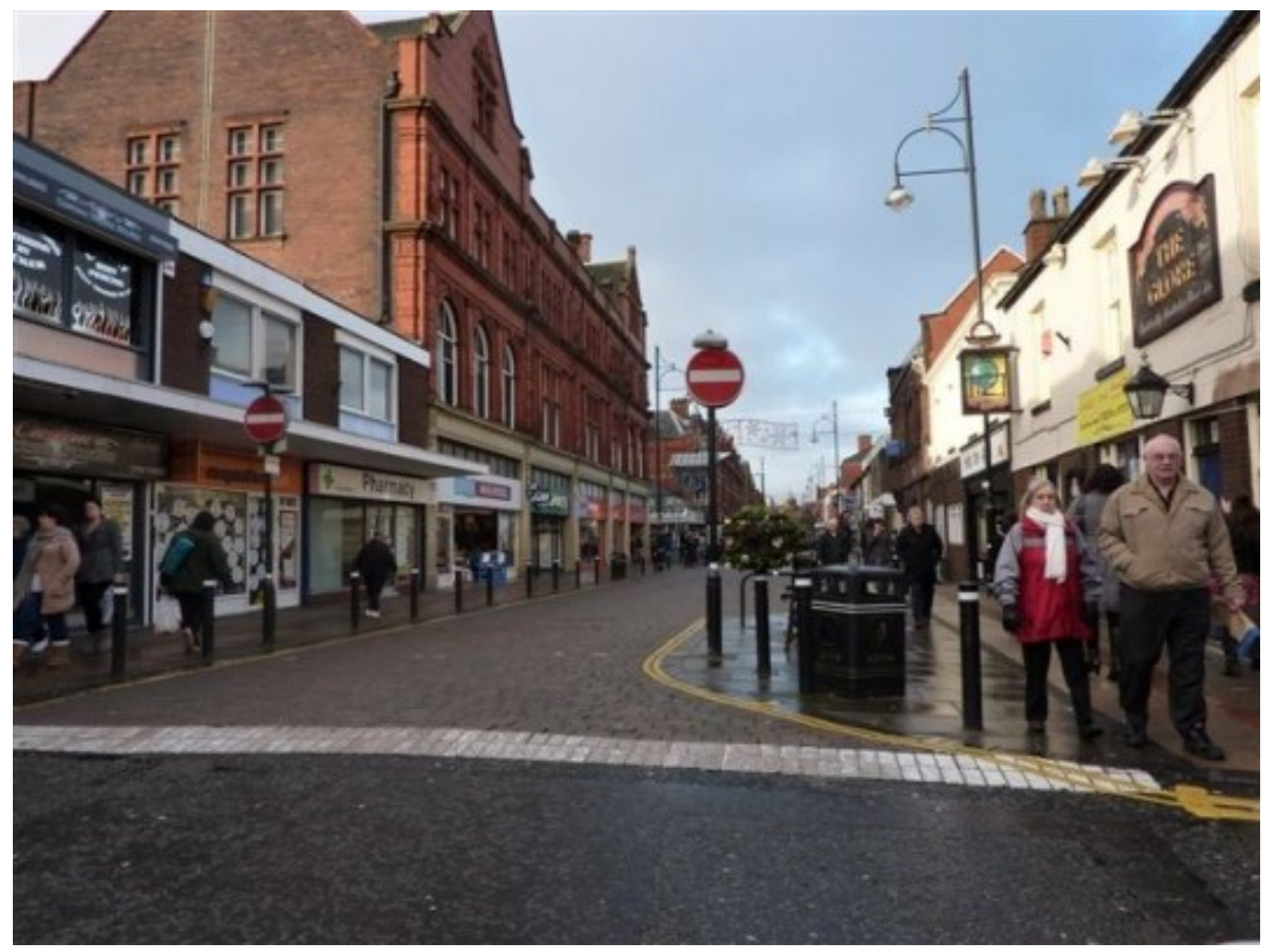

Figure 3: Bradshawgate, Leigh 
Leigh, the place Val has lived for most of her life, generally slips into the background of her consciousness but looking at a photo brings it to her notice, this unusual perspective making it look 'funny', or odd. Jacobson (2009) says that the home, like the body, is a passive element of our experience, one that 'slip[s] into the background to become the stability on which we depend without need to pay heed to it' (p. 371). Here, Val's 'home' extends to the whole of Leigh, as it is so familiar to her; it is the unnoticed background to her daily activities, until brought to her attention through looking at the photograph.

The world of predecessors becomes a part of Val's biography, and therefore her identity (Schutz 1976: 96 - 7) as Val's parents are brought into 'restorable reach', indirectly, through the building (Duranti, 2010). As well as this building, Val told me the history of most of the buildings in this and other photos, where the cinemas used to be, the shop where she bought a pram for her children. There are both personal connections to these places and at the same time she is telling me the history of Leigh as a place. This history is told here through personal stories linking to the wider world. Places and families are parts of 'webs' or 'structures of meaning' (Aspers 2004) which connect them together (Ingold 2000: 198). As with Janet's picture of the garage above, taking a photo of Leigh makes it 'look funny' to Val, and gives her a different perspective on the buildings: she hadn't told me of her parents meeting through work at the Co-op during her biographical interview. By looking at a place from the unusual perspective of the photograph my respondents were able to offer some reflections on places that are a part of their lives but not obviously important to them.

The photographs' meaning for the participants was clarified in the post-diary interview without which I would have been unable to analyse the visual data as I have. As Alexander (2013) points out, the data in a visual study still privileges the spoken and written word.

\section{How might this be useful in other research?}

These examples have demonstrated how a phenomenological approach and a variety of methods of data 'collection' (creation might be a better word) can produce rich insights into everyday, mundane activities. Taking a phenomenological approach means starting from the actors' subjective perspective (Aspers 2004). I have shown in the examples above how these different methods have enabled me to do that. This informed subjectivity (Jackson 1993: 340) allows the everyday actions of 'ordinary' people to be connected to to the theoretical perspectives, here showing how belonging is achieved through practices.

Taking a phenomenological approach afforded me a 'sideways' look at the taken-for-granted aspects of daily life: the interactions people have with their place. The written diaries allowed respondents to control the subject matter of the data (within some prescribed limits) enabling an inductive approach and reducing the influence of the researcher's preconceptions. The data is a part of the meaning structure of the participants, not that of the researcher. The visual methods in particular allowed an engagement with the materiality of the place through the eyes of the participants. I chose not to address the issue of belonging directly with my participants as I was looking for the ways in which they 'do belonging' rather than their subjective feelings about belonging. This approach allowed me to avoid relatively unproblematic ideas of what belonging 'is' and look instead at the practices which constitute belonging.

This approach would not be suitable for all types of research; taking photographs and writing (or recording) diaries assumes the participants are both willing and able to undertake these 
tasks (which not all were in this research). It is to be expected that more onerous (for the participant) research methods will reduce the pool of available participants. However some of my participants enjoyed the process of writing a diary and of thinking about their connections within their local communities.

Although the focus in this article has been on the user-driven aspects of the methods used and how the respondents gained a considerable amount of control over the production of data through the use of diaries and photos, the analysis of that data, the second order constructs (Aspers 2004), are the creation of the researcher and based on the meaning structure of the researcher, rather than that of the researched. This limits the agency afforded to participants to the creation of the data rather than extending it to the overall findings of the research. The data from a small number of participants is necessarily idiosyncratic making it harder to draw out common themes from across the participants. However, although semi-structured interviews would produce more easily comparable data, there is no one way of doing belonging: it is slippery, intangible and changes across the life-course as well as between generations. The individualistic natures of the data these methods have produced demonstrate this; although there are similarities across the participating families it is difficult to identify one comprehensive 'meaning structure' which would 'explain' how belonging is done. A more structured method of data collection might provide a more easily generalised result (Aspers 2004).

Due to the widespread use of digital cameras and camera phones and with the internet making written communication almost instantaneous, diary methods, including photo-diaries and photo-elicitation, are becoming a more common method in social research. The most productive use of photographs will often be, as here, alongside other data (Tinkler 2013). Gieryn, (2000: 483) for example, considers the use of photos and other visual methods crucial to further exploration of place in sociological work. Explanation and analysis of the photographs is nevertheless likely to be through the written word (Alexander 2013), although David Seamon (1990) has used a phenomenological approach to analysing photographs. Mixed user-driven methods such as these can open up the perspective of the research and bring in aspects a researcher would not have considered, not being privy to the life-worlds of the participants. Choosing to focus on families has given a detailed insight into the lives of groups of local people. Interviewing in couples and family groups also introduced an extra dimension through the different, often personal, conversations which took place. Interviewing small friendship groups or couples, as well as family groups, could enhance other research into the more ephemeral aspects of social life. It is to be hoped that this research will act as an exemplar of these useful and perhaps less used research approaches to privilege the voices of the participants in research into their lives.

\section{References:}

Ahmed, S 2007 'A Phenomenology of Whiteness', Feminist Theory, Vol. 8, No. 2, p. 149 168

Alexander, V D 2013 'Views of the Neighbourhood: A Photo-Elicitation Study of the Built Environment' Sociological Research Online, Vol. 18, Issue 1

Aspers, P 2004 'Empirical Phenomenology An Approach for Qualitative Research' Papers in Social Research Methods, Qualitative Series No. 9, London School of Economics and Political science Methodology Institute 
Bell, C \& Newby, H 1971 Community Studies An introduction to the sociology of the local communit. London: George Allen and Unwin Ltd

Bertaux, D \& Delcroix, C 2000 Case histories of families and social processes Enriching sociology in Chamberlayne P, Bornat J \& Wengraf T, eds The Turn to Biographical Methods in Social Science Comparative issues and example. Abingdon, Oxon: Routledge, p. 71 - 89

Bhabha, H K 1996 Culture's In-Between in Hall S \& du Gay P, eds Questions of Cultural Identity London: Sage, p. 53 - 60

Blokland, T 2001 'Bricks, Mortar, Memories: Neigbourhood and Networks in Collective Acts of Remembering' International Journal of Urban and Regional Research, Vol. 25 No. 2, p. 269-283

Bourdieu, P 1977 Outline of a Theory of Practice Cambridge: Cambridge University Press

Brah, A 2002 'Global mobilities, local predicaments: globalization and the critical imagination' Feminist Review, Vol. 70, p. 30 - 45

Casey, E 2001 'On Habitus and Place: Responding to My Critics' Annals of the Association of American Geographers, Vol. 91, No. 4, p. 716 - 723

Christensen, A.-D 2009 'Belonging and Unbelonging from an Intersectional Perspective' Gender, Technology and Development, Vol. 13, No.1, p. 21 - 41

Connerton, P 1989 How Societies Remember Cambridge: Cambridge University Press de Certeau, M 1984 The Practice of Everyday Life London: University of California Press

Degnen, C 2005 'Relationality, place, and absence: a three-dimensional perpective on social memory' The Sociological Review, p. 729 - 44

Duranti, A 2010 'Husserl, Intersubjectivity and Anthropology' Anthropological Theory, Vol. 10, No. 1 - 2, p. 16 - 35

Eberle, T 2013 'Phenomenological Sociology Reconsidered: On the New Orleans Sniper' Human Studies

Emmel, N \& Clark, A 2009 'The Methods Used In Connected Lives: Investigating Networks, Neighbourhoods, and Communities' ESRC National Centre for Research Methods Working Paper Series <www.ncrm.ac.uk>

Ferguson, H 2006 Phenemenological Sociology Insight and Experience in Modern Society London: Sage

Fortier, A.-M 1999 'Re-Membering Places and the Performance of Belonging(s)' Theory Culture \& Society, Vol. 16, No. 2, p. 41 - 64 
Frede, D 2006 The Question of Being: Heidegger's Project in: Guignon, C ed. The Cambridge Companion to Heidegger Cambridge: Cambridge University Press, p. 42-69

Gieryn, T 2000 'A Space for Place in Sociology' Annual Review of Sociology, Vol. 26, p. 463 $-96$

Gray, J 1999 'Open Spaces and Dwelling Places: Being at home on hill farms in the Scottish Borders' American Ethnologist, Vol. 26 No. 2, p. 440-460

Heidegger, M 1962 Being and Time Oxford: Blackwell

Hermanns, H 2004 Interviewing as an Activity in: Flick, U, von Kardorff, E \& Steinke, I eds A Companion to Qualitative Researc. London: Sage Publications Ltd, p. 209-213

Husserl, E 1964 The Idea of Phenomenology The Hague: Nijhoff

Ingold, T 2000 The Perception of the Environment Essays on livelihood, dwelling and skill. Abingdon: Routledge

Ingold, T 2008 'Bindings against boundaries: entanglements of life in an open world' Environment and Planning A, Vol. 40, p. 1796 - 1810

Jackson, M 1993 'Knowledge of the Body' Man New Series, Vol. 18, No. 2, p. 327 - 345

Jacobson, K. 2009 'A developed nature: a phenomenological account of the experience of home' Continental Philosophy Review, Vol. 42, p. 355 - 373

Jones, S 2010 'Negotiating Authentic Objects and Authentic Selves: Beyond the Deconstruction of Authenticity' Journal of Material Culture, Vol. 15, No. 2, p. 181 - 203

Latham, A 2003 'Research, performance, and doing human geography: some reflections on the diary-photograph, diary-interview method' Environment and Planning A, Vol. 35, p. 1993 $-2017$

Lawler, S 2005 'Disgusted subjects: the making of middle-class identities' The Sociological Review, p. 429 - 226

Leach, N 2002 'Belonging: towards a theory of identification with place' Perspecta, Vol. 33 Mining Autonomy, p. 126-133

Martin, A K 1997 'The Practice of Identity and and Irish Sense of Place' Gender, Place and Culture, Vol. 4, No. 1, p. 89 - 119

May, V 2011 'Self, Belonging and Social Change' Sociology, Vol. 45, No. 3, p. 363 - 378

Merleau-Ponty, M 1962 Phenomenology of Perception London: Routledge \& Kegan Paul Ltd Miller, D 2012 How Many Qualitative Interviews is Enough? NCRM, p. 31 $<$ www,ncrm.ac.uk> 
Moore G, Croxford B, Adams M, Refaee M, CoxT, Sharples S, 2008 'The photo-survey research method: capturing life in the city' Visual Studies, Vol. 23, No. 1, p. 50 - 62

Morgan, D H J 2005 'Revisiting "communities in Britain"' The Sociological Review, p. 641 657

Pink, S 2006 The Future of Visual Anthropology Engaging the senses Abingdon: Routledge

Said, E 2000 Out of Place A Memoir London: Granta Publications

Savage M, Bagnall G, \& Longhurst B 2005 Globalization and Belonging London: Sage

Schutz, A 1962 Collected Papers I The Problem of Social Reality The Hague: Martinus Nijhoff Publishers

Schutz, A1976 Collected Papers II Studies in Social Theory The Hague: Martinus Nijhoff

Schutz, A \& Luckmann, T 1974 The Structures of the Life-World London: Heinemann

Seamon, D 1990 'Awareness and Reunion: A Phenomenology of the Person-World Relationship as Portrayed in the New York Photographs of Andre Kartesz' in L. Zonn (Ed.), Place Images in Media: Portrayal, Experience and Meaning p. 31 - 61 Savage, Maryland: Rowman and Littlefield.

Skeggs, B 2009 'Haunted by the Spectre of Judgement: Respectability, Value and Affect in Class Relations' in: Sveinsson, K P ed. Who Cares About the White Working Class Runnymede Trust, p. 36 - $44<$ www.runnymedetrust.org $>$

Stacey, M 1960 Tradition and Change A Study of Banbury Oxford: Oxford University Press Tinkler, P 2013 Using Photographs in Social and HIstorical Research London: Sage

Vaitkus, S 2000 Phenomenology and Sociology in Turner B S ed The Blackwell Companion to Social Theory second editio. Oxford: Blackwell, p. 270 - 298

Valentine G, Sporton D, \& Nielsen K B, 2009 'Identities and belonging: a study of Somali refugee and asylum seekers living in the UK and Denmark' Environment and Planning D: Society and Space, Vol. 27, No. 2, p. 234 - 250

Vergunst, J 2010 'Rhythms of Walking: History and Presence in a City Street' Space and Culture, Vol. 13, No. 4, p. 376 - 388

Zimmerman, D \& Wieder, D L 1977 'The Diary: Diary-Interview Method' Journal of Contemporary Ethnography, Vol. 5, p. 479 - 498 